\title{
Da abordagem comunicativa à perspectiva acional no curso de letras português / francês da Universidade Federal de Sergipe
}

\author{
Weslin de Jesus Santos Castro ${ }^{1}$ \\ Renilson Santos Oliveira ${ }^{2}$
}

\begin{abstract}
Resumo: O presente artigo traz um estudo sobre a passagem da Abordagem Comunicativa (AC) à Perspectiva Acional (PA) havida no curso de Letras Português/Francês da Universidade Federal de Sergipe (UFS) no primeiro semestre de 2012, com o objetivo de refletir sobre a pertinência dos princípios metodológicos preconizados pela PA - enfoque bastante discutido nos últimos anos pelos teóricos da Didática de Línguas Estrangeiras - no ensino e na aprendizagem do Francês Língua Estrangeira (FLE) em formação inicial. Para tanto, buscamos elucidar os elementos metodológicos da AC e da PA nas aulas das disciplinas de Língua Francesa; apresentamos os componentes curriculares do curso de Letras em questão, mostrando a correspondência entre as ementas das referidas disciplinas e o conteúdo programático previsto pelos manuais Forum e Version Originale; e, finalmente, registramos e discutimos as considerações feitas pelos docentes de francês do Departamento de Letras Estrangeiras da UFS em relação aos efeitos do referencial metodológico da PA em suas aulas de FLE na formação de futuros professores.
\end{abstract}

Palavras-chave: Abordagem Comunicativa. Perspectiva Acional. Ensino. Aprendizagem. FLE.

\section{From communicative approach to action perspective in the portuguese/french letters course of the Federal University of Sergipe}

\begin{abstract}
The present article brings a study on the transition from the Communicative Approach (CA) to the Actional Perspective (AP) occured on the BA in Language Teaching (Portuguese/French) at the Federal University of Sergipe (UFS) on the first term of 2012, aiming at the reflection on the relevance of the methodological principles foreboded by the AP - focus widely discussed over the last years by the theorists of the Didactics of Foreign Languages - on the teaching and learning of French as a Foreign Language (FFL) in initial education. Thus, we have tried to elucidate the methodological elements of the CA and AP on the French Language lessons; we have presented the curricular components of the referred Teaching Language Course, by showing the correspondence between the referred disciplines syllabus and the programmatic contents provided by the Forum and Version Originale manuals; and, finally, we have registered and discussed on the considerations made by the

\footnotetext{
${ }^{1}$ Licenciado em Letras Português/Francês pela Universidade Federal de Sergipe. Professor e coordenador pedagógico da Aliança Francesa de Aracaju. Professor da rede pública de ensino do Estado de Sergipe. e-mail: ws_weslin@yahoo.com.br / telefone: (79) 88515814.

2 Doutor em Letras pela Universidade de São Paulo. Mestre pela mesma universidade. Graduado pela Universidade Federal de Sergipe. Professor efetivo de Língua Francesa do Departamento de Letras Estrangeiras da Universidade Federal de Sergipe e coordenador do Curso de Letras: português/ francês da mesma universidade. e-mail: renilov@ig.com.br / telefone: (79) 88418141.
} 
French Language teachers of the UFS Foreign Languages Department regarding the effects of the PA methodological referential in their classes of FFL in the training of teachers-to-be.

Keywords: Communicative Approach. Actional Perspective. Teaching. Learning. FFL.

\section{INTRODUÇÃO}

Ao longo de vinte anos de formação em língua francesa, o curso de Letras Português/Francês da Universidade Federal de Sergipe tem se utilizado da Abordagem Comunicativa como referencial metodológico para o ensino de francês como língua estrangeira. Em 2012, houve um investimento em um novo referencial metodológico - Perspectiva Acional - bastante difundido e objeto de discussão entre didatólogos, professores e alunos no mundo inteiro. Assim, esta reorientação metodológica suscita uma reflexão sobre o seu real poder de formação de futuros professores, que poderá ser utilizada em outros contextos formativos, por outras instituições, com objetivos diferentes daqueles visados pelo Departamento de Letras Estrangeiras (DLES) da UFS.

Diante disso, o presente artigo refletirá sobre a utilização desta perspectiva nas disciplinas de Língua Francesa do referido curso, tendo por objetivo coletar dados sobre a execução dos princípios da PA nesta formação inicial. Aqui, entenderemos formação inicial como aquele primeiro contato que um indivíduo tem com o instrumental teórico e prático de uma dada área do saber. Essa formação, assegurada por uma Instituição de Ensino Superior, é responsável pelo delineamento da identidade profissional do indivíduo.

Sendo assim, este trabalho justifica-se academicamente, haja vista a mudança do manual adotado pelos professores do DLES, isto é, a substituição do Forum pelo Version Original (V.O.) no primeiro semestre de 2012, o que marca uma mudança na formação em FLE dos estudantes de Letras francês, pois cada um destes manuais está pautado em uma postura metodológica diferente. 
Esta pesquisa também é pertinente porque a realizamos enquanto aluno em vias de conclusão do curso de Letras: português/francês desta universidade, tendo feito o mesmo percurso formativo do nosso campo de pesquisa e tendo apresentado este estudo na monografia exigida ao término desta licenciatura, sob a orientação do Prof. Dr. Renilson Santos Oliveira.

Na sua atual configuração, o curso de Letras Português/Francês da Universidade Federal de Sergipe, de acordo com a Resolução $n^{\underline{0}}$ 61/2007/CONEPE/UFS ${ }^{3}$, apresenta-se sob duas habilitações, a matutina e a noturna, dividida em oito e dez períodos, respectivamente. Visto que se trata de uma licenciatura, este curso propõe formar docentes potencialmente capazes de lecionar a língua portuguesa e a língua francesa, e suas respectivas literaturas, nas instituições públicas e privadas de ensino fundamental e médio da Educação Básica Brasileira, articulando coerentemente teoria e prática e estando aberto às atualizações próprias de sua docência.

Tendo em vista o contexto apresentado acima, questionamos o real efeito da PA nas aulas de FLE em uma Instituição de Ensino Superior situada no Brasil, e mais especificamente, no Nordeste brasileiro. Dito de outra forma: professores e alunos, participantes deste processo de ensino e aprendizagem inseridos neste quadro institucional, constituem-se de fato atores sociais? Como possibilidade de resposta, formulou-se a hipótese de que, para isso, seria necessário encarar o espaço sociodiscursivo da sala de aula como legitimador da PA, de modo que as práticas discursivas e as atividades didáticas desenvolvidas aí fossem consideradas como uso real da língua-alvo. Nos próximos itens, buscaremos confirmar ou não essa hipótese.

\footnotetext{
$\overline{{ }^{3} \text { Esta foi alterada pela Resolução } n^{0}}$ 28/2013/CONEPE/UFS, cuja principal mudança, para efeito da discussão feita neste artigo, é a inclusão da disciplina Língua Francesa VIII como obrigatória.
} 
ISSN: 2317-2347 - Vol. 7, Ano 4, NN 2 - 2015

\section{O ENSINO E A APRENDIZAGEM DO FRANCÊS NO CURSO DE LETRAS: PORTUGUÊS/FRANCÊS}

Conforme relato oral de um docente do curso de Letras francês do DLES/UFS, para as disciplinas de Língua Francesa, no período de 2003 a 2011, os professores de francês adotaram o manual Forum, que orientava os conteúdos programáticos e garantia a progressão dos níveis de língua.

Publicado em 2000, esse livro traz em seu guia pedagógico informações precisas de que fora concebido de acordo com os princípios metodológicos da Abordagem Comunicativa, como bem explicita a seguinte passagem em seu texto:

Les principes méthodologiques qui ont présidé à l'élaboration de FORUM et qui fondent la démarche pédagogique s'inscrivent dans la lignée des orientations didactiques actuelles pour ce qui est à la fois des compétences langagières visées et des objectifs communicatifs poursuivis ${ }^{4}$. (BAYLON,

2000, p. 6, grifo nosso)

No primeiro semestre de 2012, após praticamente uma década de utilização desse manual, os docentes de francês da UFS adotaram o Version Originale com a intenção de testarem na formação em Letras uma nova orientação metodológica. Esse manual, publicado em 2009, é baseado na Perspectiva acional, tal como se lê no prefácio:

Version Originale se situe résolument dans la lignée de Rond-Point (...) premier cours de FLE à suivre cette nouvelle perspective. Mais Version Originale met en plus à profit l'expérience de cette première collection ainsi que les réflexions et propositions didactiques de ces toutes dernières années. Les didacticiens de langues-cultures ont pu en effet, depuis la publication du Cadre européen, mieux penser les implications concrètes du passage de l'agir communicationnel à la

\footnotetext{
${ }^{4}$ Os princípios metodológicos que nortearam a elaboração do FORUM e que fundamentam a utilização pedagógica se inscrevem na linha das orientações didáticas atuais, entendidas como competências de comunicação visadas para assegurar os objetivos comunicativos pretendidos. (Tradução nossa)
} 
ISSN: 2317-2347 - Vol. 7, Ano 4, NN 2 - 2015

nouvelle perspective de l'agir social' $^{5}$. (DENYER, 2009, p. 2, grifo nosso)

\subsection{Ensinando e aprendendo francês pela Abordagem Comunicativa}

Ao longo dos anos, com a evolução dos estudos sobre o processo de ensino e aprendizagem de um idioma estrangeiro, foram surgindo diversas metodologias, de modo que umas cediam lugar às outras, sempre buscando superar as limitações deixadas pela anterior. A reflexão que se fez em torno dessas metodologias foi e ainda é postulada sob vários aspectos: papéis desempenhados por professor e alunos, intenção de comunicação destes, concepção de língua desenvolvida em cada época e lugar da cultura na aprendizagem. Assim, aprendia-se um idioma estrangeiro para, dentre outros objetivos: ler textos na língua-alvo e os traduzir em língua-materna (Metodologia Tradicional); adquirir automatismos linguísticos capazes de traduzir o pensamento e com estes chegar à comunicação oral, a priori (Metodologia Direta); desenvolver uma eficaz percepção global de frases ditas na língua-alvo (Metodologia Audiovisual); dentre tantos outros.

Em continuidade a essa sequência de metodologias, surge a Abordagem Comunicativa ${ }^{6}$ nos anos 70, em um contexto de estreitamento sócio-político-cultural da Europa face ao desenvolvimento econômico. Este novo referencial metodológico surge na tentativa de preencher as lacunas deixadas pela Metodologia Audiovisual, pois como afirma Oliveira (2002, p. 71):

\footnotetext{
${ }^{5}$ Version Originale se situa de fato na linha de Rond-Point (...), primeiro manual de FLE a seguir esta nova perspectiva. Mas Version Originale se serviu mais da experiência desta primeira coleção, assim como das reflexões e propostas didáticas destes últimos anos. Com efeito, os didáticos de línguasculturas puderam, desde a publicação do QECR, pensar melhor nas implicações concretas da passagem da perspectiva do agir comunicacional à nova perspectiva do agir social. (Tradução nossa)

${ }^{6}$ Fizemos este corte histórico até a Abordagem Comunicativa, pois, além de anteceder, é ela que estabelece uma linha tênue com a Perspectiva Acional, objeto do nosso estudo.
} 
Os referidos métodos significaram um avanço em relação ao método tradicional, mas passaram, a partir de um certo momento a receber críticas de diversas ordens, na medida em que não preparavam os alunos para situações espontâneas de comunicação.

Recebendo o termo de "abordagem", ela designa um aporte metodológico que conduz a um olhar mais amplo sobre o ensino e a aprendizagem de LE, um olhar que não está voltado apenas para um aspecto desse processo, pois tem sua filiação teórica em mais de uma corrente dos estudos linguísticos: a Gramática GerativoTransformacional de Chomsky, a Abordagem Situacional na Grã-Bretanha, a teoria pragmática sobre os atos de fala dos filósofos da linguagem Austin e Searle, e as contribuições trazidas pela sociolinguística de Hymes. Germain (1993, p. 202) corrobora dizendo que:

C'est la convergence de ces quelques courants de recherche ainsi que l'avènement de différents besoins linguistiques dans le cadre d'une Europe élargie (marché commum, Conseil de l'Europe, etc) qui a en définitive donné naissance à "l'approche communicative". Il faut dire cependant que cette expression n'est apparue que vers les années 1975, quelque temps après l'avènement du mouvement communicatif même, dont les limites demeurent encore assez mal définies ${ }^{7}$.

Um dos postulados fundamentais da $\mathrm{AC}$, e o que estabelece um verdadeiro hiato entre esta e as metodologias anteriores, é a compreensão da língua enquanto instrumento de comunicação, ou para ser mais específico, a língua enquanto ferramenta de interação social, na qual os sujeitos são constituídos enquanto interlocutores que negociam o tempo todo o(s) sentido(s) daquilo que foi (ou está sendo) comunicado. Sob este ponto de vista, a língua já não é mais vista como um

\footnotetext{
${ }^{7}$ Foi a convergência destas correntes de pesquisa assim como o advento de diferentes necessidades linguísticas no contexto de uma Europa ampliada (mercado comum, Conselho da Europa, etc) que definitivamente fez surgir a abordagem comunicativa. É preciso dizer, entretanto, que esta expressão apareceu apenas no ano 1975 aproximadamente, algum tempo depois do advento do próprio movimento comunicativo, cujos limites permanecem ainda mal definidos. (Tradução nossa)
} 
fim em si mesmo, mas um meio pelo qual as pessoas interagem na sociedade. Dessa maneira, o aluno aprende uma língua estrangeira para comunicar-se, para interagir.

Quando se pensa em comunicação ou interação, entram em discussão dois conceitos apresentados por Germain (1993), também pontuados pela AC: a situação comunicativa e a intenção comunicativa. O primeiro termo se refere ao contexto no qual a língua é utilizada, ou seja, a posição social dos interlocutores, sua formação, idade, gênero, o local da comunicação, a duração. $O$ segundo se refere em geral aos atos de fala (ou atos de linguagem), dos quais cada falante - em uma dada proporção - se serve no seu cotidiano linguístico. Como exemplo disso, podemos citar: saudar alguém, dar uma ordem ou pedir licença. Na conjunção destes dois fatores é que ocorreria de fato a interação social, a partilha dos efeitos de sentidos produzidos pelos falantes. De modo mais específico, a finalidade de aprender uma LE é desenvolver as habilidades comunicativas (compreensão e expressão, oral e escrita) de acordo com a situação e a intenção de comunicação.

El enfoque comunicativo de enseñanza de lenguas, por consiguiente, defiende el desarollo en el aprendiz de la competencia comunicativa (...) De ello se desprende que aprender una lengua extranjera no es simplesmente aprender su sistema lingüístico formal, sino también aprender a usarla en situaciones contextuales adecuadas 8 . (SANTANA, 2005, p. 95-96)

Para tanto, como forma de aproximar o aporte teórico da AC às práticas discursivas dos estudantes de FLE, geralmente o trabalho é iniciado com a exposição destes a situações comunicativas: diálogos trazidos pelo livro, textos didaticamente

\footnotetext{
${ }^{8} \mathrm{O}$ enfoque comunicativo de ensino de línguas, por conseguinte, defende o desenvolvimento no aluno da competência comunicativa (...) Disso decorre que aprender uma língua estrangeira não é simplesmente aprender seu sistema linguístico formal, mas aprender a usá-la em situações contextuais adequadas. (Tradução nossa) $\mathrm{O}$ termo enfoque aqui é usado como correlato do termo abordagem, pois como afirma o próprio Santana (2005), ele permite uma maior flexibilidade na aplicação dos pressupostos linguísticos, psicopedagógicos e didáticos.
} 
criados nos diversos gêneros textuais, documentos autênticos ${ }^{9}$. Em seguida, passa-se a compreensão destas situações, segundo a intenção comunicativa - atos de fala empregados - e segundo as formas linguísticas utilizadas, a partir das quais será feito um estudo mais detido sobre as estruturas próprias do francês. Depois deste itinerário, tendo o aluno já sistematizado certos códigos linguísticos com exercícios de gramática, sobretudo, ele é levado a produzir textos orais ou escritos de acordo com os enunciados dados pelos professores.

Para a produção oral, um dos dispositivos didáticos usados pelos professores de francês na prática da AC é o jeu de rôles (diálogo), no qual os alunos recebem o enunciado de uma situação comunicativa hipotética, porém possível na vida real, como por exemplo: "Você acaba de chegar a Paris para um intercâmbio. Bastante cansado e com fome, você entra em um restaurante. Simule o diálogo". Para encenála, os estudantes precisam lançar mão de sua competência linguística, código de língua já adquirido, de sua competência pragmática (referente aos atos de linguagem da vida cotidiana, como saudar, ler o cardápio e fazer o pedido) e de sua competência sociocultural (conhecimento sobre os hábitos dos franceses à mesa).

Em uma aula de FLE sob os parâmetros comunicativos, os papéis desempenhados por professor e aluno também são diferentes em relação às metodologias anteriores. O professor passa a ser um facilitador, porque viabiliza o contato do aluno com a língua estrangeira a partir de diversos documentos; um analista, porque verifica os centros de interesse dos alunos quando da preparação das aulas; um modelo, como aquele que faz um uso adequado dos vários registros de língua; um interlocutor, com quem os alunos podem testar suas aquisições linguísticas. O aprendiz, por sua vez, passa a ser um comunicador que se serve de

\footnotetext{
9 Textos orais ou escritos (reportagens, vídeos, romances, músicas, entre outros) constantes em suportes que não foram criados a priori para fins didáticos e que circulam no cotidiano comunicativo dos falantes nativos.
} 
suas competências linguísticas para agir sobre seu interlocutor, fazendo-o reagir. Disso decorre que o espaço-classe se torna um laboratório, em que os estudantes fazem seus contatos e experiências com a língua-alvo, com vistas a alcançar determinado nível de proficiência.

É a exposição a todo esse possível processo de aprendizagem exposto acima, vislumbrado pelos docentes de francês do DLES, associado a um ideal investimento pessoal nos estudos em autonomia por parte dos estudantes, que garantirá a estes a possibilidade de internalizarem paulatinamente as competências comunicativas devidas a sua formação superior e necessárias à docência.

Portanto, com a utilização do Forum nas aulas das disciplinas de Língua Francesa, o trabalho é feito a partir dos princípios da AC e centrado nas necessidades e no perfil de aprendizagem do público-alvo, no caso desta pesquisa, dos estudantes do curso de Letras francês.

\subsection{Da Abordagem comunicativa aos primeiros efeitos da Perspectiva Acional}

Nos últimos anos, sobretudo com a publicação do Quadro Europeu Comum de Referência (QECR) para as línguas, em 2000, a Perspectiva Acional entrou nos debates sobre o ensino e a aprendizagem de línguas estrangeiras, consequentemente do FLE. De acordo com as discussões havidas nos últimos anos, a tônica é de que a opção primeira deste documento seja o ensino, a aprendizagem e a avaliação sob o enfoque dito acional. Daí porque, pode-se considerar que, após o surgimento dele, esta nova perspectiva tem sido objeto de constante reflexão entre os didatólogos.

Assim, observa-se atualmente uma influência considerável dos princípios preconizados pelo QECR na elaboração dos manuais, na concepção de cursos, nas avaliações oficiais de proficiência, entre outros. "Le CECR apparait en effet de plus en plus comme la nouvelle doxa incontournable, bien au-délà des environnements 
pour lesquels il a été pensé10." (CASTELOTTI, 2011, p. 12). Essa influência do QECR, como bem assinala esse trecho, vai além do continente europeu, para o qual foi concebido.

O QECR foi criado pela Divisão de políticas linguísticas do Conselho da Europa, visando a "rapprocher les États du continent européen en les incitant à adopter des démarches communes dans le domaine culturel et politique ${ }^{11 "}$ (BESSE, 2011, p. 152). Ou seja, a princípio este documento foi concebido a partir de uma necessidade do contexto europeu de, por meio de um procedimento comum no que se refere a políticas linguísticas, promover os valores culturais partilhados pelos países membros do Conselho da Europa, viabilizando um diálogo mais intenso e uma convivência mais harmoniosa. Dessa forma, a política linguística empenhada pelo QECR põe em evidência o plurilinguismo como condição sine qua non para o exercício da cidadania europeia.

Diante disso, seria possível pensar em uma aplicabilidade do QECR fora da Europa? E ainda, aqui no Brasil, onde não há ainda uma promoção efetiva do plurilinguismo para assegurar uma mobilidade de seus cidadãos entre as fronteiras com outros países? Para tanto, à primeira vista, não há meio plausível senão que contextualizá-lo, isto é, fazer o filtro daquilo que ele propõe como novidade para o ensino e a aprendizagem de um idioma estrangeiro e daquilo que é realizável em contexto não europeu, no caso desta pesquisa, em contexto institucional no Nordeste brasileiro. No entanto, o que se tem visto é uma espécie de supervalorização deste documento que não prescreve, apenas orienta, e, mesmo sua contextualização de fato não dá conta das necessidades e dos perfis locais de aprendizagem.

\footnotetext{
${ }^{10}$ Com efeito, o QECR aparece cada vez mais como a nova doxa incontornável, bem além dos meios para os quais ele foi pensado. (Tradução nossa)

${ }^{11}(. .$.$) aproximar os países do continente europeu levando-os a adotar procedimentos comuns no$ âmbito cultural e político. (Tradução nossa)
} 
ISSN: 2317-2347 - Vol. 7, Ano 4, NN 2 - 2015

La plupart des tentatives de contextualisation interviendraient effectivement comme des simples déplacements, moyennant quelques adaptations de la part principalement technique, donc superficielle du CECR, sans pour autant s'interroger sur les nécessaires reconstructions de sens qu'il imposerait une telle entreprise $^{12}$. (CASTELOTTI, 2011, p. 13-14)

Para o Brasil, mais especificamente Sergipe, em que os manuais de francês utilizados são produzidos na Europa, portanto concebidos a partir do QECR, faz-se necessária a contextualização deste documento, de maneira que suas orientações assumam uma cor local. Nessa tarefa, os Parâmetros Curriculares Nacionais de Língua estrangeira têm contribuído na reflexão sobre o processo de ensino e aprendizagem de LEs no Brasil. Publicado em 1998, este documento elaborado por educadores brasileiros traz orientações didáticas, e não prescrições, para a promoção das LEs na educação brasileira. Levando em consideração as diversidades regionais do Brasil, os PCNs também comungam de algumas ideias comunicativas e acionais do QECR.

A aprendizagem de uma língua estrangeira deve garantir ao aluno seu engajamento discursivo, ou seja, a capacidade de se envolver e envolver outros no discurso. Isso pode ser viabilizado em sala de aula por meio de atividades pedagógicas centradas na constituição do aluno como ser discursivo, ou seja, sua construção como sujeito do discurso via Língua Estrangeira. Essa construção passa pelo envolvimento do aluno com os processos sociais de criar significados por intermédio da utilização de uma língua estrangeira. (MINISTÉRIO DA EDUCAÇÃO BRASILEIRA, 1998, p. 19, grifo nosso)

\footnotetext{
${ }^{12} \mathrm{~A}$ maioria das tentativas de contextualização intervêm efetivamente como simples deslocamentos, viabilizando algumas adaptações principalmente da parte técnica, portanto superficial, do QECR, sem para isso se interrogar sobre as necessárias reconstruções de sentido que impõe tal empenho. (Tradução nossa)
} 
Seguindo esse raciocínio pode-se dizer que o aluno, enquanto sujeito de um discurso age no mundo fazendo uso da língua estrangeira nas várias habilidades comunicativas.

Nesse sentido, acredita-se que, no curso de Letras francês, com a substituição paulatina do Forum pelo V.O., haja uma reorientação das práticas dos professores de francês e também uma mudança na postura dos estudantes face à aprendizagem do referido idioma. Pois, a partir de então, o ensino e aprendizagem de FLE passam a ser conduzidos também de acordo com os princípios metodológicos da PA, tão recorrente no QECR.

A Perspectiva acional, precedente ao QECR, tal como afirma Santana (2005, p. 100), "es la tendencia que se consolida em los años noventa, como uma manera innovadora de trabajar la lengua extranjera en el aula. ${ }^{13 "}$ Recebendo o termo de "perspectiva", ela não constitui um corpus metodológico à parte, diferente, mas um "caminho" didático que leva a termo todo o percurso proposto pela AC, pautando-o na ação. “La enseñanza mediante tareas no es un método. Es una propuesta evolucionada dentro del enfoque comunicativo (...) $)^{14}$." (ZANÓN, 1999, p. 16)

Ainda a título de esclarecimento da terminologia adotada para PA, a noção de ação, conforme Bérard (2009), já estava implícita na AC, mas agora, com a PA, ela assume outro caráter: o aluno, em um dado contexto comunicativo e motivado por certa intenção comunicativa, adquire competências linguísticas e é levado a agir não sobre seu interlocutor, mas em parceria com este, em uma espécie de ação conjunta.

\footnotetext{
${ }^{13}$ Esta é a tendência que se consolida nos anos noventa, como uma maneira de trabalhar a língua estrangeira na aula. (Tradução nossa)

${ }^{14} \mathrm{O}$ ensino mediante tarefas não é um método. É uma proposta evoluída dentro do enfoque comunicativo. (Tradução nossa). Mais à frente veremos que as tarefas correspondem ao instrumental didático principal da PA.
} 
(...) l'articulation entre approche communicative et perspective actionnelle: le passage d'un apprentissage individuel (que l'on peut associer à la centration sur l'apprenant, caractéristique de l'approche communicative et qui s'exerce parfaitement lors des jeux de rôles et des simulations) à un apprentissage colaboratif et solidaire misant sur un agir social et communicationel (que l'on peut associer, pour tenter la parallèle), à une centration sur le groupe qui trouve son expression dans la pédagogie du projet ${ }^{15}$. (ROSEN, 2009, p. 8)

Esse agir, assumindo então um novo aspecto, configura-se como o motor da aprendizagem. Assim sendo, a finalidade de se aprender uma língua estrangeira consiste em adquirir competências linguísticas que tornem um indivíduo capaz de agir conjuntamente, que façam deste um ator social, seja na sala de aula, seja no contexto externo a esta.

Para tanto, um dos dispositivos didáticos preconizados pela PA é a tarefa. Em linhas gerais, ela é definida como “toute visée actionnelle que l'acteur se représente comme devant parvenir à un résultat donné en fonction d'un problème à résoudre, d'une obligation à remplir, d'un but qu'on s'est fixé16." (CONSEIL DE L'EUROPE, 2001, p. 16). O ator social, que, nesse caso, é o aluno, cumpre tarefas também quando ele consegue déplacer une armoire, jouer aux cartes (deslocar um armário, jogar uma partida de cartas), ações que resultam em um constructo identificável, ainda que este não seja de natureza linguística. Nesse sentido, o QECR identifica os seguintes tipos de tarefa:

\footnotetext{
15 (...) a articulação entre abordagem comunicativa e perspectiva acional: a passagem de uma aprendizagem individual (que podemos associar à concentração no aluno, característica da abordagem comunicativa que se dá perfeitamente na realização dos jeux de rôles, diálogos, e das simulações) para uma aprendizagem colaborativa e solidária pautada em um agir social e comunicacional (que podemos associar, para fazer um paralelo, a uma concentração no grupo que encontra sua expressão na pedagogia do projeto). (Tradução nossa)

${ }^{16}$ todo foco acional visado pelo ator que deve chegar a um dado resultado em função de um problema a resolver, de uma obrigação a cumprir, de um objetivo fixado. (Tradução nossa)
} 
1. les tâches "cibles", "de répétition" ou "proches de la vie réelle" choisies en fonction des besoins de l'apprenant hors de la classe ou du contexte de l'apprentissage;

2. les tâches de communication pédagogique fondée sur la nature sociale, interactive et immédiate de la situation de classe ; les apprenants s'y engagent dans un "faire semblant" accepté volontairement pour jouer le jeu de l'utilisation de la langue cible ; ces tâches ont des résultats identifiables ;

3. les tâches de pré-communication pédagogique constituées d'exercices spécifiquement axés sur la manipulation décontextualisée des formes ${ }^{17}$. (BÉRARD, 2009, p. 40-41)

Em uma aula de FLE no contexto visado por esta pesquisa, o trabalho feito com as tarefas é justificável, uma vez que, tendo o estudante feito todo o roteiro de aprendizagem sob os parâmetros comunicativos, o que não é excluído no QECR, ele é conduzido a realizar tarefas, construindo suas competências comunicativas enquanto ator social. Em contraste com as produções (orais e escritas) propostas pela AC, acredita-se que as tarefas, sobretudo aquelas de "repetição ou próximas da vida real", estão ancoradas em um contexto real de comunicação. Isso porque, partindo de uma necessidade real no mundo comunicativo dos alunos, elas resultam em um objeto concreto, observável. Em outras palavras, “(...) le rôle des tâches communicatives consistent à fournir un cadre interactionnel permettant à l’apprenant de construire des compétences langagières adaptées à des situations de communication authentique ${ }^{18}$." (GRIGGS, 2009, p. 83)

\footnotetext{
${ }_{17} 1$. as tarefas "alvo", "de repetição" ou "próximas da vida real" escolhidas em função das necessidades do aluno fora da aula ou do contexto de aprendizagem. 2. as tarefas de comunicação pedagógica fundadas na natureza social, interativa e imediata da situação de aula, os alunos se engajam nisso em um "fazer de conta aceito" voluntariamentell para atuar no jogo da utilização da língua-alvo; estas tarefas têm resultados identificáveis; 3. as tarefas de pré-comunicação pedagógica constituídas de exercícios especificamente focados na manipulação descontextualizada das formas. (Tradução nossa)

${ }^{18}(\ldots)$ o papel das tarefas comunicativas consiste em fornecer um contexto interacional que permita ao aluno construir competências linguísticas adaptadas a situações de comunicação autêntica. (Tradução nossa)
} 
Exemplificando, na tarefa: "Você está procurando fazer contato com um francófono para treinar seu francês. Para isso, você se inscreve no site www.contactsfrancophones e começa sua busca", podemos prever o domínio dos atos de fala apresentar-se, identificar-se, como condição necessária para a consecução dos objetivos, pois aí, o estudante terá de dar-se a conhecer para conseguir encontrar alguém com quem comunicar. Nesse sentido, há na tâche uma nuança maior de contexto real de comunicação, pois o espaço "virtual" é um contexto comunicativo bem acessível aos alunos, ao passo que a situação apresentada pelo jeu de rôles no item anterior pode não ser tão presente no cotidiano linguístico de todos os estudantes.

Por conseguinte, tendo em vista que o aluno é um ator social que age conjuntamente utilizando de modo autônomo seus conhecimentos linguísticos, o papel desempenhado pelo professor sob os parâmetros acionais assume outra natureza. Nesse sentido, ele se torna um gestor das atividades em sala de aula, alguém que ensina os alunos a aprenderem, a buscarem material linguístico, fazerem suas escolhas, visando sempre à tarefa a realizar.

Il ne s'agit plus uniquement pour lui de déverser des savoirs (et d'en vérifier la restitution) ou de diriger des exercices (et d'en contrôler l'exécution) mais de fonctionner comme le coach d'un sportif; bien évidemment, il lui arrivera encore de donner une explication sur la bonne position du poignet à revers (sur la morphologie des démonstratifs ou du subjonctif), d'entraîner à faire des lobs ou des passings (à accorder des participes ou à conjuguer des verbes), mais l'objectif restera le match ou la tâche et, dès lors, il ne suffit plus pour lui de "tenir un discours sur..."19 (DENYER, 2009, p. 154)

\footnotetext{
${ }^{19}$ Para ele [o professor], já não se trata unicamente de despejar saberes (e de verificar a restituição destes) ou de conduzir exercícios (e de controlar a execução destes), mas de fazer o papel do treinador de um esportista; evidentemente, ser-lhe-á necessário dar uma explicação sobre a posição certa do punho ao rebater a bola (sobre a morfologia dos demonstrativos ou do subjuntivo), de ensinar a fazer lobs ou passings (a concordar particípios ou a conjugar verbos), mas o objetivo continua sendo a partida, ou a tarefa e, desde então, não lhe basta mais "sustentar um discurso sobre" (Tradução nossa)
} 


\section{COMPONENTES CURRICULARES DA FORMAÇÃO INICIAL EM LETRAS: PORTUGUÊS/FRANCÊS}

De acordo com o Art. $7^{0}$ da Resolução mencionada no início deste artigo, a estrutura curricular dessa dupla habilitação organiza-se a partir de conteúdos de caráter específico, profissional e complementar, dando maior ênfase à aquisição dos conhecimentos teóricos que ao trabalho com as disciplinas reservadas para a prática docente. Cabe lembrar que não se quer aqui discutir o currículo do curso citado, pois esse não é o foco deste trabalho. Faz-se referência à sua estrutura curricular apenas para situar o contexto institucional em que o referido curso está inserido.

Sendo assim, o curso de Letras português/francês visa aos seguintes objetivos:

I. Geral: formar profissionais interculturalmente competentes, capazes de lidar de forma crítica, com as linguagens, especialmente a verbal nos contextos oral e escrito, e conscientes de sua inserção na sociedade e das relações com o outro.

II. Específicos:

a) habilitar professores de português e francês para o ensino fundamental e médio;

b) garantir aos futuros professores destas línguas a formação de um espírito crítico capaz de nortear sua prática docente, tanto local quanto nacionalmente;

c) orientar os futuros docentes nas novas concepções sobre a natureza da língua e seu ensino-aprendizagem, de maneira que a prática docente atenda às necessidades pragmáticas de comunicação por um lado, e às necessidades e diferenças dos alunos, por outro; (...) (CONEPE/UFS, 2013, p.2)

Em se tratando das matérias de ensino da Língua francesa, o estudante tem o duplo desafio: aprender a língua estrangeira, adquirindo um nível plausível para a docência, e ter o domínio dos procedimentos didáticos em FLE para a atuação em sala de aula. Com essas disciplinas, objetiva-se desenvolver nos estudantes, dentre 
outras habilidades previstas no projeto pedagógico do Curso de Letras Português/Francês, as competências de:

a) compreender, avaliar e produzir textos em português e francês;

b) descrever e justificar as peculiaridades fonológicas, morfológicas, lexicais, sintáticas e semânticas dos idiomas português e francês;

c) apreender criticamente as obras literárias, em ambas as línguas, não somente através de uma interpretação derivada do contexto direto com elas, mas também da mediação de obras de crítica e de teoria literárias;

d) pesquisar e articular informações linguísticas, literárias e culturais;

e) conhecer os fundamentos, a natureza e os princípios da pesquisa em linguística, $\mathrm{e}$,

f) ter consciência do papel social das línguas como elemento cultural, econômico e político. (CONEPE/UFS, 2013, p. 2)

Dentre essas disciplinas de ensino, apenas as disciplinas nomeadas de "Língua Francesa" foram contempladas com a reorientação metodológica indicada no item anterior, sendo, portanto, priorizadas na observação dos aspectos metodológicos feita por esta pesquisa.

Divididas em oito semestres obrigatórios, estas disciplinas propõem um curso de FLE em nível básico (Língua Francesa I, II e III), intermediário (Língua Francesa IV, V e VI) e avançado (Língua Francesa VII e VIII). Desse modo, conforme o ementário estabelecido pela mesma Resolução, em nível básico, são priorizadas as habilidades de compreensão e expressão oral; em nível intermediário, as habilidades de compreensão e expressão escritas. Nestas disciplinas, o estudo do francês é conduzido a partir dos "atos de linguagem, dos aspectos culturais e das estruturas morfossintáticas e fonéticas." (CONEPE/UFS, 2013, p. 14) 
Em nível avançado (Língua Francesa VII e VIII), a ênfase é dada aos diferentes registros de língua, às expressões idiomáticas e aos falsos amigos, tendo sua prática garantida por atividades realizadas pelos alunos na aula ou fora dela.

Disso, pode-se dizer que, embora o curso de Letras francês não se caracterize oficialmente comunicativo, o texto das ementas previstas para as disciplinas de Língua Francesa refletem uma postura de ensino e aprendizagem inscrita na Abordagem Comunicativa, haja vista o largo uso de um vocabulário típico desse referencial metodológico, tais como habilidades comunicativas, atos de linguagem (ou de fala), componente linguístico e cultural, explicitados no item anterior.

Tendo em vista as exigências próprias de cada uma destas disciplinas de Língua Francesa, os três volumes do Forum foram utilizados como instrumento didático principal nas aulas de FLE, de 2003 a 2011.

O percurso de aprendizagem do FLE proposto por cada unidade do Forum apresenta a seguinte ordem ${ }^{20}$ : tomando como exemplo a Unidade 1 do volume 1 , cujo universo comunicativo se resume nos primeiros contatos em LE, o estudante explora inicialmente do Contrat d'apprentissage, em que constam as competências linguísticas, pragmáticas e interculturais a serem desenvolvidas; na seção Forum, ele é introduzido no universo comunicativo da unidade por meio de diálogos e imagens. A seguir, na seção Agir-réagir, os alunos são expostos a situações comunicativas com atividades de compreensão oral e escrita; nas páginas Connaître et reconnaître, eles fazem um estudo detido das formas gramaticais presentes na unidade. Depois, com a seção S'exprimer eles adquirem ferramentas linguísticas previstas para os atos de fala típicos das situações comunicativas apresentadas, sendo-lhes propostas atividades de produção oral (jeu de rôles) e escrita. Por fim, na seção Interculturel, são apresentados alguns aspectos culturais franceses e francófonos concernentes ao universo

\footnotetext{
${ }^{20}$ Embora o manual apresente essa ordem, o professor tem autonomia para fazer o percurso que achar devido ao grupo-classe.
} 


\section{Revista Letras Raras}

ISSN: 2317-2347 - Vol. 7, Ano 4, NN 2 - 2015

comunicativo da unidade. Assim, todo o roteiro de aprendizagem acontece sob os parâmetros da AC.

Com a mudança de manual indicada no item anterior, mudou também o recorte das disciplinas de Língua Francesa e sua correspondência com as unidades do livro utilizado, agora o V.O.

Esse manual, em cada uma de suas unidades, propõe a aprendizagem do FLE conforme a seguinte estrutura: na seção Premier contact, os estudantes são sensibilizados a alguns aspectos da realidade francesa e apresentados à tarefa final a ser executada, bem como das ferramentas e estratégias necessárias para fazê-lo; com as páginas Textes et contextes, eles são familiarizados com vários documentos orais e escritos, a partir dos quais eles interagem em sala com os colegas. Na seção $\grave{A} l a$ découverte de la langue, o trabalho de compreensão é centrado em certos recursos linguísticos particulares; na página Outils, o estudo é voltado para pontos de gramática e, na seção Outils en action, os alunos são levados a realizar tarefas de comunicação pedagógica. No final de cada unidade, como dispositivo pedagógico para a produção oral ou escrita, o V.O. traz a tarefa final ou próxima da vida real, a ser cumprida pelos alunos.

Como se pôde ver, o processo de aprendizagem segundo o V.O. está focado na PA, uma vez que, por meio da realização de uma tarefa final, ele conduz teoricamente a construção de um produto observável, que se pode avaliar a partir do sentido e da forma linguística. Tomando como exemplo a Unidade 1 do livro 1, a tarefa final proposta é a criação de cartazes para a sala de aula contendo informações sobre os alunos, palavras, frases e perguntas úteis para o espaço-classe.

Dessa forma, o V.O. sugere um procedimento ideal, mas nem sempre real, de aula de FLE, levando os estudantes a agirem enquanto usuários da língua-alvo e evidenciando um contexto autêntico de comunicação. 


\section{DOCENTES FACE À FORMAÇÃO PROMOVIDA PELO CURSO DE LETRAS: PORTUGUÊS/FRANCÊS}

Visto que estamos tratando do processo de ensino e aprendizagem de uma língua estrangeira, e de modo mais específico, da reorientação metodológica havida na formação em FLE proposta pelo DLES/UFS, um dos elementos a ser considerado é sem dúvida o professor. Por isso, registraremos aqui o depoimento de alguns docentes de francês desse departamento sobre a temática desta pesquisa.

Para tanto, foi aplicado um questionário aos quatro professores responsáveis pelas disciplinas de Língua Francesa no semestre letivo de 2012.2 e a um dos professores encarregados da matéria de ensino metodologia do FLE. Dentre estes, um não respondeu à sondagem. O questionário aplicado se compôs de três partes: na primeira, nove questões sobre dados pessoais; na segunda, nove questões sobre o processo de ensino e aprendizagem do FLE; na terceira, um espaço aberto para crítica ou sugestão sobre algum aspecto não contemplado pelo questionário. Com isso, quisemos verificar a posição desses docentes em relação aos primeiros efeitos da PA no contexto de ensino e aprendizagem visado por este trabalho.

É preciso esclarecer que optamos por não aplicar outro questionário aos estudantes, pois, consideramos à época que a passagem para a nova orientação metodológica ainda era muito recente no referido curso, de modo que não obteríamos dados significativos por parte deles, tendo em vista que tais resultados dependem de um tempo processual.

\subsection{Docentes com a palavra: orientação metodológica e manual adotado}

Embora os referenciais metodológicos presentes no curso de Letras francês sejam a AC e a PA, de acordo com os dados coletados, a maioria dos professores afirma trabalhar de maneira coerente recorrendo aos princípios didáticos das 


\section{Revista Letras Raras}

ISSN: 2317-2347 - Vol. 7, Ano 4, NN 2 - 2015

metodologias já adotadas anteriormente, com vistas a atender às necessidades de aprendizagem que surgem no percurso de formação dos futuros professores de francês. Pois, segundo P4, é preciso "fazer com que esses alunos conheçam a língua nos seus meandres [sic], como estimulamos que os nossos alunos da universidade, futuros professores, conheçam." Essas e outras necessidades de formação nem sempre são preenchidas pela $\mathrm{AC}$ e a $\mathrm{PA}$, uma vez que, como afirmam vários profissionais da didática de línguas estrangeiras, nenhum manual se mostra completo, isto é, se pensarmos aqui na importância dada ao manual adotado dentro de uma dada concepção metodológica no processo de formação em LE.

Daí a importância do papel do professor na complementação com outros materiais didáticos para que atinjam os objetivos estabelecidos. P4 acrescenta que "é praticamente impossível assumir que em sala de aula podemos ter apenas uma abordagem".

Nesse sentido, podemos perceber uma postura eclética desses docentes, tal como define Oliveira (2002, p. 76) ao fazer menção à posição de Puren, didatólogo francês e defensor também da P.A.:

... o ecletismo é perceptível no ensino de línguas quando os tipos de práticas observados são mais numerosos e diversificados do que os previstos pela metodologia de referência do professor. (...) Essa ação eclética pressupõe, segundo Puren (1994), além da diversificação de procedimentos e materiais didáticos, a reutilização de certas concepções metodológicas antigas.

Essa postura eclética dos professores não impede, entretanto, o uso do manual de FLE recentemente adotado no curso de Letras: português/francês, pois, de acordo com a resposta de P1 "adotar um manual não é a mesma coisa que adotar o referencial metodológico em que ele se fundamenta. Qualquer manual pode ser utilizado avec un autre régard [sic]. Isso depende de quem o utiliza, das condições em que é utilizado."

No que concerne ao manual V.O., os professores ficaram um pouco divididos em suas opiniões. Alguns se mostraram reticentes quanto a sua suficiência didática 
para o alunado do curso de Letras francês, de modo que precisa ser acrescido de material complementar para atender às necessidades referidas mais acima. Por ter pouco tempo de trabalho nesta Instituição de ensino superior, P4 preferiu não se pronunciar a respeito do manual, pois precisaria analisá-lo melhor. De maneira mais detida, dois deles pontuaram os seguintes aspectos negativos encontrados nesse manual:

- “... a questão da progressão do conteúdo programático não corresponde à realidade do ensino do francês na UFS." (P2)

- “... o V.O. apresenta um certo desequilíbrio no desenvolvimento das competências: trabalha bem mais as de compreensão..." (P1)

- "Algumas tarefas apresentadas são complexas, difíceis de serem realizadas." (P1)

Ainda sobre o V.O., P3 reconhece que este manual atende em parte às expectativas de ensino e aprendizagem do FLE na UFS, assinalando apenas alguns recursos exigidos para seu uso pleno, como $\mathrm{TBI}^{21}$, laboratório multimídia, dos quais este contexto institucional ainda não dispõe.

Em seguida, fazendo um contraponto entre a AC e a PA nesta formação universitária, os professores afirmam que a diferença concreta entre ambos referenciais é a proposta de tarefa trazida pela PA. Sobre isso, P1 se pronuncia dizendo que:

(...) pode-se observar que no V.O. elas são, em maior parte, mais próximas do real, menos parecidas com simulações, mais voltadas a grupos pequenos e grandes, demandam mais informação. Realizamse como etapas para cumprirem uma tarefa maior.

\footnotetext{
${ }^{21}$ Em francês, Tableau Blanc Interactif (Lousa interativa).
} 
ISSN: 2317-2347 - Vol. 7, Ano 4, NN 2 - 2015

Dessa forma, os professores foram unânimes em afirmar que o ensino de FLE no curso de Letras francês a partir do atual referencial metodológico apresenta certas limitações, pois o aporte didático proposto pela PA "exige ferramentas que não temos", como afirma P4. Uma dessas ferramentas, provavelmente a mais necessária, seria um contexto real de comunicação em língua-alvo, de modo que o estudante fosse conduzido a agir e reagir enquanto verdadeiro ator social. Por se tratar de um processo de aprendizagem, e não de aquisição, como sugere Stephen Krashen ${ }^{22}$ no conjunto de seus escritos, para que isso se efetivasse, deveríamos promover no espaço-classe esse contexto real de comunicação, aproximando o processo de aprendizagem à realização de tarefas mais voltadas a situações da vida real dos estudantes, tornando assim legítimo o uso da PA nas aulas de FLE. Em outras palavras:

En bref, il faudrait reconnaître pleinement l'authenticité du lieu social que constitue la classe, ainsi que la legitimité et la fonctionnalité des tâches et de rôles qu'il induit (Moulin, 2008) dans une dynamique actionelle pleinement constructive ${ }^{23}$. (CHINI, 2010, p. 174)

Todavia, os professores acreditam ser um tanto forçoso encarar o espaço da sala de aula como um lugar legítimo de comunicação, de sorte que as práticas

\footnotetext{
${ }_{22}$ Professor emérito da Universidade da Califórnia (EUA), conhecido por sua Teoria da Aquisição de Segunda Língua. Segundo este autor, em um processo de aquisição o indivíduo adquire a língua de maneira inconsciente - dada a imersão em que se encontra. Já em um processo de aprendizagem, que é o caso nesta monografia, ele faz uso de estratégias didáticas de maneira consciente para aprender, haja vista o ensino institucionalizado que recebe.

${ }^{23}$ Resumindo, seria necessário reconhecer plenamente a autenticidade do lugar social que constitui a aula, assim como a legitimidade e a funcionalidade das tarefas e dos papeis que ele induz (Moulin, 2008), em uma dinâmica acional plenamente construída. (Tradução nossa)
} 
discursivas de professores e alunos fossem consideradas aí como uso real do FLE. A afirmação de P1 ilustra isso:

Os princípios teóricos que embasam o V.O. são bastante justificáveis (...) se aceitarmos que o aprendiz é um "ator social" num contexto estrangeiro, um usuário de uma língua estrangeira tanto quanto um aprendiz dessa língua num contexto não estrangeiro. Acho isso meio forçado, o que nos faz refletir sobre adquirir e aprender uma língua.

Logo, conforme testemunho unânime dado pelos docentes, o ensino e a aprendizagem de FLE nas disciplinas de Língua Francesa do curso de Letras: português/francês do DLES/UFS sob os parâmetros acionais é legitimo quando se faz o filtro daquilo que é realmente factível. Para isso, é fundamental que as orientações metodológicas da PA sejam adaptadas ao contexto institucional enfocado neste trabalho.

\section{CONSIDERAÇÕES FINAIS}

Neste artigo buscamos refletir sobre a passagem da Abordagem Comunicativa à Perspectiva Acional na formação inicial em Letras Português/Francês, verificando a pertinência dessa última nas disciplinas de Língua Francesa do DLES/UFS.

Dessa forma, pudemos vislumbrar os primeiros efeitos da PA no processo de ensino e aprendizagem do FLE neste contexto institucional. Dentre eles, identificamos a princípio a necessidade de caracterização da sala de aula como espaço legítimo de comunicação real entre os alunos, de modo que estes sejam de fato atores sociais.

Para a concretização disso, a língua-alvo funcionaria como um meio pelo qual os estudantes atingiriam um objetivo concreto e ao mesmo tempo significativo para a aprendizagem. Por exemplo, depois de uma unidade que versa sobre a apresentação pessoal em língua estrangeira, os estudantes entrevistariam um 


\section{Revista Letras Raras}

ISSN: 2317-2347 - Vol. 7, Ano 4, NN 2 - 2015

professor de LE nativo, ainda não conhecido deles, para cumprir a tarefa: estabelecer contato com um nativo próximo de seu entorno e descobrir alguns traços biográficos.

Entretanto, de acordo com a pesquisa desenvolvida neste trabalho, foi possível observar que é forçoso falar de comunicação autêntica dos alunos na língua- alvo, pois, dentre as ferramentas que nos faltam para a realização disso, está o contexto real de comunicação que demanda dos usuários da língua uma ação, seja de ordem linguística ou não.

Assim sendo, constatamos que a hipótese formulada no início desta pesquisa não se confirma, pois, embora o contexto sociodiscursivo do espaço-classe seja necessário e eficaz para a proficiência em LE, ele não se configura em um contexto real de uso da língua-alvo. Isso porque ele carece, conforme a discussão feita aqui, dos mesmos elementos que legitimam de fato uma comunicação autêntica no cotidiano linguístico dos falantes nativos.

Portanto, o estudante de Letras: português/francês do DLES/UFS reveste-se durante sua formação inicial da qualidade de aprendiz e não de usuário da língua, pois este último mantém um contato constante com o idioma estrangeiro, seja porque é nativo ou porque habita no país onde utiliza a língua em imersão; diferentemente da posição assumida pelo estudante de Letras em francês do DLES/UFS diante da língua que lhe é estrangeira e promovida institucionalmente. Todavia, a condição de aprendiz do FLE em contexto artificial e em situações de simulação comunicativa não diminui de modo algum sua postura ativa no processo de aprendizagem de uma LE, pelo contrário, aumenta ainda sua responsabilidade na aquisição do nível de proficiência adequado para sua atuação na docência.

\section{REFERÊNCIAS}

BAYLON, C. et al. Forum - méthode de français. (Livre de l'élève) Paris: Hachette, 2000. 


\section{Revista Letras Raras}

ISSN: 2317-2347 - Vol. 7, Ano 4, NN 2 - 2015

. Forum - méthode de français. (Guide pédagogique) Paris: Hachette,

2000.

BÉRARD, É. Les tâches dans l'enseignement du FLE: rapport à la réalité et dimension didactique. Le français dans le monde: recherches et applications. Paris, n. 45, p. 36 - 44, janvier 2009.

BESSE, H., Six remarques autour et au-delà de la contextualisation du CECR. Le français dans le monde: recherches et applications. Paris, n 50, p. 150-162, juillet 2011.

CASTELLOTTI, V.; NISHIYAMA, J. N. Contextualiser le CECR? Le français dans le monde: recherches et applications. Paris, n. 50, p. 11- 26, juillet 2011.

CHINI, Danielle. Langage et/ou action? La perspective actionnelle favorise-t-elle vraiment l'apprentissage linguistique? Le français dans le monde: recherches et applications. Paris, n. 48, p. 164 - 175, juillet 2010.

CONEPE/UFS. Resolução n. 61 de 14 de dezembro de 2007.

CONSEIL DE L'EUROPE. Cadre européen commun de référence pour les langues: apprendre, enseigner, évaluer. Strasbourg, 2001.

DENYER, M. et al. Version Originale - méthode de français. (Livre de l'élève) Paris: 2009.

DENYER, M. La perspective actionnelle du Cadre Européen Commum de Référence et ses répercussions dans l'enseignement des langues. In : La perspective actionnelle dans l'enseignement des langues : douze articles pour mieux comprendre et faire le point. Paris: Maison des langues, 2009. p. 141 - 157.

GERMAIN, C. Évolution de l'enseignement des langues : 5000 ans d'histoire. Paris: CLÉ - International, 1993.

GRIGGS, P. A propos de l'articulation entre l'agir de l'usage et l'agir de l'apprentissage dans une approche actionnelle: une perspective sociocognitive. In : $L a$ perspective actionnelle dans l'enseignement des langues: douze articles pour mieux comprendre et faire le point. Paris: Maison des langues, 2009. p. $79-100$.

MINISTÉRIO DA EDUCAÇÃO BRASILEIRA. Parâmetros Curriculares Nacionais de Língua Estrangeira - Ensino Fundamental. Brasília, 1998.

OLIVEIRA, R. S. Ensino e aprendizagem do Francês - Língua Estrangeira no Estado de Sergipe: realidade e perspectiva. São Paulo, 2002. 231f. Dissertação (Mestrado em Letras). Faculdade de Filosofia, Letras e Ciências Humanas. Universidade de São Paulo. 
Percursos teóricos para o ensino-aprendizagem de línguas estrangeiras. In: SANTANA, G. et alli. Questões de línguas estrangeiras, línguas estrangeiras em questão. Aracaju: Editora UFS, 2005. p. 107-135.

ROSEN, É. La perspective actionnelle et l'approche par les tâches. Le français dans le monde: recherches et applications. Paris, n. 45, p. 6 - 14, janvier 2009.

SANTANA, G. Concepciones sobre la lengua, su enseñanza-aprendizaje y el papel otorgado al profesor y al alumno en los distintos enfoques metodológicos. In: . Questões de línguas estrangeiras, línguas estrangeiras em questão. Aracaju: Editora UFS, 2005. p. 71-105.

ZANÓN, J. (Coord.) La enseñanza del español mediante tareas. Madrid: Edinumen, 1999.

Grade curricular do curso de Letras Português/Francês. Disponível em: $<$ http://www.daa.ufs.br//>. Acesso em 14.abr.2013

Recebido: em 30 de Agosto de 2015 Aceito: em 02 de outubro de 2015 